\title{
De las ciencias a la vida o sobre la productividad en la Ciénaga de Ayapel y su praccis*
}

\author{
Elvia María González Agudelo** \\ Néstor Jaime Aguirre Ramírez ${ }^{* * *}$
}

Recibido: 18/06/2013 - Aceptado: 16/03/2015

\begin{abstract}
Resumen
La estrategia didáctica praccis busca traducir dialógicamente algo extraño en el mundo de las ciencias, en algo cercano o quizá propio, en el mundo de la vida. Lo científico, lo extraño son los resultados de la investigación sobre la productividad en la ciénaga de Ayapel, Colombia, que es mediado por la estrategia didáctica praccis, para facilitar la circulación del conocimiento. Esta investigación está configurada en cuatro partes: una primera, que expone rigurosamente cómo es la productividad en la ciénaga de Ayapel; una segunda, donde se describen los postulados de la estrategia praccis; una tercera, donde se explica cómo se construye la estrategia didáctica con los conocimientos sobre la productividad de la ciénaga, y una cuarta, donde se muestra cómo se aplicó la estrategia que dio como el resultado la aceptación entre los pobladores de Ayapel, del establecimiento de la relación entre los campos semánticos y los eslabones de la estrategia praccis.
\end{abstract}

Palabras clave: productividad, ciénaga de Ayapel, praccis, hermenéutica y circulación del conocimiento.

\footnotetext{
Este artículo es el resultado del objetivo específico de la investigación titulada "Del mundo de las ciencias al mundo de la vida: un modelo hermenéutico para la circulación del conocimiento" (Aprobada, según acta CODI $\mathrm{N}^{\circ} 356$ y financiada por la Universidad de Antioquia) que reza: Aplicar y evaluar el modelo hermenéutico para traducir el lenguaje científico en lenguaje cotidiano en torno al objeto de estudio agua.

** Doctora en Ciencias Pedagógicas. Profesora Universidad de Antioquia. Calle 67 No. 53-108. Of. 9-429. Tel. 2195738. Grupo DIDES, Didáctica de la Educación Superior. elvia.gonzalez@udea.edu.co

*** Doctor en ciencias naturales. Profesor Universidad de Antioquia. Calle 67 No. 53-108. Of. 20-403. Tel. 2198600. Facultad de Ingeniería, Escuela Ambiental, Grupo GeoLimna. nestor.aguirre@ude.edu.co
} 


\section{Science to life or on productivity in the Ayapel'S swamp and its Praccis}

\section{ABSTRACT}

The praccis teaching's strategy looks for, to translate dialogically, something strange, something from the world of science, into an approaching or perhaps something of his self, in the world of life. The scientist facts in this case, the strange thing, are the results of research on productivity in Ayapel's swamp, Colombia, which is mediated by the praccis teaching strategy, in order to come closer to the people, who live in the same location, to facilitate the movement of knowledge.

This research is made up of four parts: a first rigorously exposition of how productivity in Ayapel's swamp is; a second which describes the praccis strategy; third which explains how to build the teaching strategy with knowledge from the marsh productivity and fourth, showing how the strategy was implemented and the results were that the semantic fields and their relationship with the links of the strategy praccis were attractive to residents of Ayapel.

Key words: productivity, Ayapel's swamp, praccis, hermeneutics and circulation of knowledge teaching strategy. 


\section{INTRODUCCIÓN}

El sistema cenagoso de Ayapel se encuentra ubicado en el departamento de Córdoba, Colombia. Este sistema es un conjunto de biotopos acuáticos y terrestres, a través de los cuales se intercambia materia y energía respondiendo al pulso de inundación [1].

En el trópico suramericano existe aún un número elevado de sistemas cenagosos. Particularmente en Colombia el número de estos ambientes es aproximadamente 1900 cuerpos de agua de considerable extensión [2]. En Colombia las llanuras inundables corresponden a cuerpos de agua de gran extensión y poca profundidad donde la disponibilidad del recurso íctico es vital para las comunidades humanas.

Los humedales figuran entre los ecosistemas más productivos del mundo [3]. Pese a ello, en los sistemas cenagosos es probable que una fracción importante de la producción primaria sea exportada a otros ambientes, y así la plusvalía en tanto la generación de biomasa por parte de los organismos autótrofos no permanezca en el lugar donde se generó sino que sea llevada a otros ecosistemas, como consecuencia del alto grado de apertura de estos ambientes, bajos tiempos de retención hidráulicos influidos por el régimen hidrológico y los pulsos de inundación, y una fuerte interacción con reoambientes, convirtiéndose así en exportadores de biomasa.

Por lo anterior, se podría postular que la productividad biológica en los sistemas cenagosos se encuentra estrechamente relacionada con las plantas acuáticas y la cadena de detritus en sus raíces, en especial si se ha removido el bosque ripario.

En la ciénaga de Ayapel, existe una presencia importante de plantas flotantes en época de aguas altas, especialmente del género Eichhornia spp. Este género, en conjunto con un número importante de gramíneas colonizan el espejo de agua y acumulan en sus raíces y tallos cantidades importantes de microorganismos y detritus [4].

Como plantean Aguirre y otros [4], en la cadena de pastoreo en el sistema cenagoso de Ayapel, la fotosíntesis realizada por las algas y las plantas provee la biomasa para los herbívoros, pero la cantidad de energía que se aprovecha en el proceso de la fotosíntesis es tan solo el $2 \%$. De este $2 \%$ solo es aprovechado un $12 \%$ por los herbívoros, y así sucesivamente se agota la energía en el sistema. Los depredadores reciben una parte pequeña de la energía que fluye en la cadena. Así, por ejemplo, el fitoplancton produce en la ciénaga de Ayapel 1495,82 t/ $\mathrm{km}^{2} /$ año que se transforman en $179,50 \mathrm{t} / \mathrm{km}^{2} /$ año de zooplancteres y estas producen $19,75 \mathrm{t} / \mathrm{km}^{2} /$ año de peces planctívoros como las sardinas,

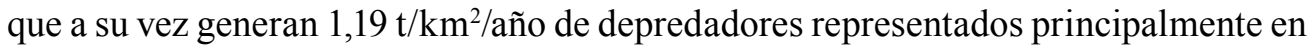
peces carnívoros y aves ictiófagas.

Por su parte, el epifiton [5] y las bacterias suministran $8770,19 \mathrm{t} / \mathrm{km}^{2} /$ año de alimento y este se transforma en 1052,42 t/ $\mathrm{Km}^{2} /$ año básicamente relacionados con peces 


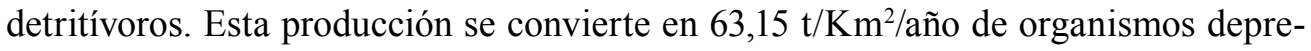
dadores. Lo anterior quiere decir que, si no hubiese factores de deterioro ambiental como la contaminación del agua, la deforestación o tala del bosque, la sobre-pesca, entre otros, la ciénaga sería un sistema altamente productivo, viviría y contribuiría a la vida de sus habitantes por una época mayor.

La estrategia didáctica denominada praccis se concibe como una experiencia hermenéutica de donde emerge un texto que se fija como estructura de sentido y funge como mediación para traducir dialógicamente, algo extraño, en el mundo de las ciencias, en algo cercano o quizá propio, en el mundo de la vida.

Una experiencia hermenéutica se concibe como "algo que no solo es vivido sino que el hecho de que lo haya sido ha tenido algún efecto particular que le ha conferido un significado duradero" [6]. Ahora bien, esa vivencia se puede fijar como un texto, "de modo que siempre podamos volver de nuevo a ella" [7]. Cuando concebimos la estrategia didáctica denominada praccis como una experiencia hermenéutica nos referimos a que los procesos de comunicación del texto, cuando se construyen y se comparten con otros, el profesor, los vive y los hace vivir en los otros, como una experiencia única e irrepetible que posibilita la formación.

Una estructura de sentido, desde la perspectiva hermenéutica, concibe los procesos de comprensión como movimientos en círculos concéntricos, donde el todo y sus partes se relacionan en fusión de horizontes; el horizonte como "el ámbito de visión que abarca y encierra todo lo que es visible desde un determinado punto" [8]. Cuando concebimos la estrategia didáctica denominada praccis como una estructura de sentido nos referimos a que es un texto didáctico que se configura como un todo con sus partes, llamadas eslabones; cada eslabón, a su vez, es un todo con sus respectivas partes; un todo y sus partes que se desplazan en el horizonte y que se mueven en círculos concéntricos, ampliando la comprensión, veamos:

Los eslabones de la estrategia didáctica praccis son cuatro, a saber: la motivación o el mundo de la vida, el acercamiento a los saberes o el mundo de las ciencias, el aprendizaje de los saberes científicos, y la evaluación y la auto evaluación o la formación del ser. Cada eslabón es, a la vez, un todo que contiene sus respectivas partes, así: la motivación o el mundo de la vida es el primer todo, donde sus partes son la iconografía, las preguntas de prejuicios y el diálogo. El acercamiento a los saberes o el mundo de las ciencias es el segundo todo, con sus partes: la iconografía, las preguntas de reflexión, las preguntas de comprensión, el diálogo y los juegos. El aprendizaje de los saberes científicos, como el tercer todo, con sus partes la iconografía, los juegos, las preguntas de análisis, de comparación, interpretación y de síntesis. La evaluación y la auto evaluación constituyen el cuarto todo que, a la vez, funciona como partes en 
el trayecto de los otros eslabones, pues da cuenta a partir del diálogo que genera cada pregunta de los prejuicios, la reflexión, el análisis, la comparación, la comprensión, la interpretación y la síntesis, la praccis, que posibilita la formación de quien, conscientemente la vive.

Ahora bien, cuando se va a hablar de un conocimiento científico a una comunidad que no lo ha producido, posiblemente no será comprendido; hay que encontrar, entonces, una expresión adecuada para lo que se quiere decir, hay que ir al encuentro de signos: iconos y palabras, que aclaren lo dicho. Los signos del lenguaje cotidiano son una primera mediación para decir lo que se piensa, para sencillamente hablar, y son también el vínculo para comunicar los conceptos del mundo de las ciencias, ese otro lenguaje que emana metódicamente del mundo de la vida, y que necesita ser traducido, volverse claro, para que todos podamos hablar de ello, evitar el mal entendernos y vivir mejor.

Cuando concebimos la estrategia didáctica denominada praccis, como una mediación, nos referimos a que ella en sí misma, relaciona dos mundos: el mundo objetivo, "como conjunto de todas las entidades sobre las que son posibles enunciados verdaderos" [9], con el mundo de la vida, el compartido por todos, "el campo universal de toda praccis real y posible" [10]. Además, en cada uno de sus eslabones, habitan los iconos, las preguntas y los juegos, como mediaciones que mueven dichos eslabones, en círculos concéntricos, rumbo a la comprensión del lenguaje científico que, además de ser mediado, es traducido.

La traducción es pasar "lo manifestado de modo extraño o ininteligible al lenguaje inteligible por todos" [6]. Es hacer propio lo ajeno, cercano lo lejano, conocido lo extraño. Cuando concebimos la estrategia didáctica, denominada praccis, como una traducción nos referimos a que alguien que habita los dos mundos, alguien que habla los dos lenguajes, alguien que es un gran conversador, descodifica el lenguaje científico en íconos, preguntas y juegos, que, encadenando en cada eslabón, arrastran motivos y vivencias de esa cultura receptora que merece en su dignidad saber más y mejor de lo que lo rodea.

\section{MATERIALES Y MÉTODOS}

La estrategia didáctica praccis fungió como medición para traducir las investigaciones científicas, realizadas sobre redes tróficas y productividad en el sistema cenagoso de Ayapel, facilitando la circulación de los resultados, de eso extraño, los conocimientos científicos, en el mundo de la vida, en el mundo habitado por las comunidades del municipio de Ayapel, para hacer cercano eso científico que emerge de su propia ciénaga.

Así es como los saberes científicos son abordados, en un primer momento, desde el mundo de la vida y los prejuicios de los lectores; luego se desarrollan los cono- 
cimientos de resultados de las investigaciones con preguntas para la comprensión, acompañadas de imágenes, esquemas y juegos que generan reflexión para el aprendizaje de los saberes científicos, que se van adquiriendo con el desarrollo de preguntas de análisis, comparación, interpretación y síntesis para inducir a los interlocutores a crear algo nuevo con el conocimiento. Por último, se encontrarán aspectos básicos para los procesos de evaluación del aprendizaje y la autoevaluación o la formación realmente adquirida. Esta mediación también está acompañada de un glosario y su respectiva bibliografía. Veamos:

\section{RESULTADOS Y DISCUSIÓN}

\subsection{Primer eslabón}

El primer eslabón consiste en la motivación o el mundo de la vida, donde sus partes son la iconografía, las preguntas de prejuicios y el diálogo.

El profesor, como traductor, representa el mundo de la vida en iconos: fotografías, diagramas, mapas, entre otros, para motivar al diálogo a sus interlocutores sobre aquello que los rodea, en este caso la ciénaga de Ayapel. La vida misma, sentida como algo que nos asombra, es el lugar en donde afloran las motivaciones. "Lo vivencial (...) es el lugar de las motivaciones" [11]. Es el inicio de una experiencia que los otros, los habitantes de la ciénaga, deben sentir como única e irrepetible, deben sorprenderse ante la belleza de un fenómeno natural que ven a diario. El mundo de la vida es la fuente originaria del saber, de la motivación por el saber, de la formación. Mediante la observación directa de un icono puede generarse una percepción de los sentidos que genere recordación en el ser y que, a la vez, lo motive. En este caso los iconos con los cuales el profesor dio inicio a su conversación fueron una fotografía y un mapa, como se observa en las figuras 1,2 y 3.

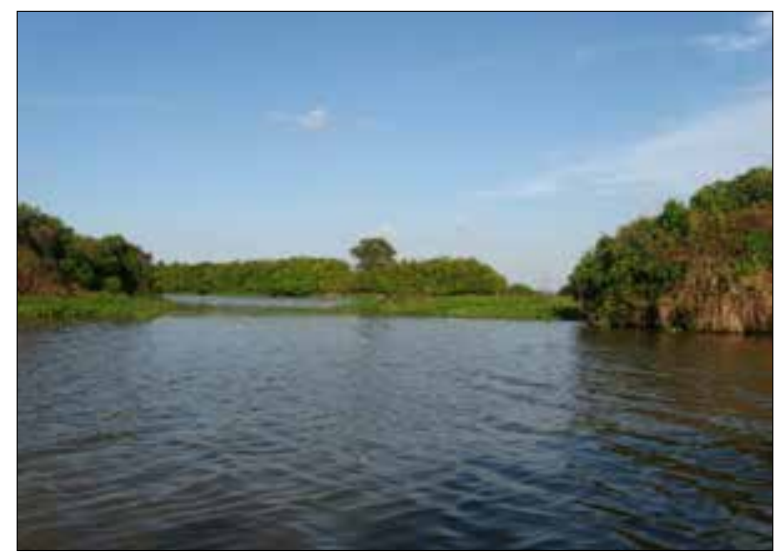

Figura 1. Fotografía de la ciénaga de Ayapel Fuente: [4]. 


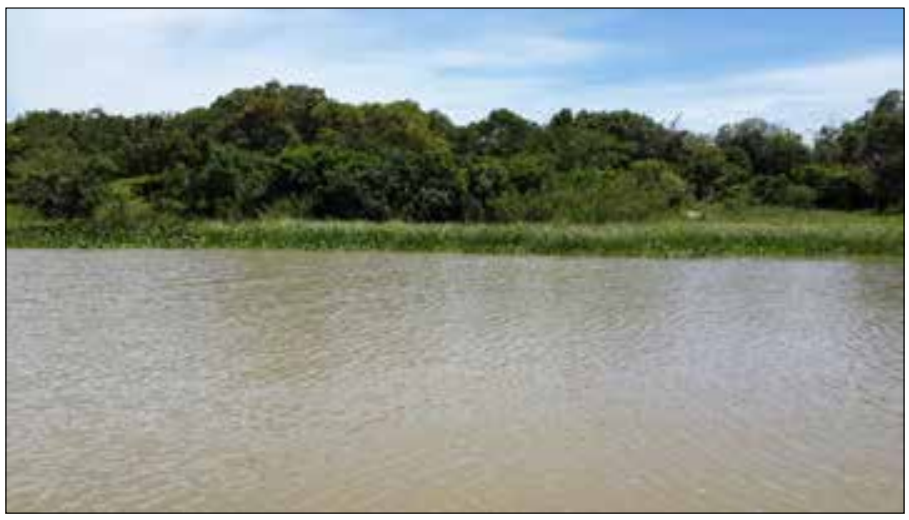

Figura 2. Fotografía reciente de la ciénaga de Ayapel. Fuente: elaboración propia



Figura 3. Ubicación geográfica de la ciénaga de Ayapel Fuente: [4] 
Una vez los iconos son observados, alguien puede sentirse motivado, afloran sus prejuicios, creencias y emociones, juicios previos, experiencias anteriores que devienen de la herencia cultural, del mundo circundante; se da inicio a la conversación, que el profesor lleva en tono de preguntas, "preguntas que se plantean y que tienen su sentido en su motivación" [8]. Son preguntas sugestivas que abren posibilidades; son preguntas como preludio para el tránsito al conocer; son preguntas del tipo:

- ¿Qué observa en las imágenes de la ciénaga de Ayapel?

- ¿Qué es lo que más le gusta de la ciénaga de Ayapel?

- ¿Qué cree usted que produce la ciénaga de Ayapel?

- ¿Qué siente al mirar estas imágenes?

Qué observa, qué le gusta, qué cree, qué siente... percepciones que motivan; la motivación es el punto de inicio para querer obrar, para desear ir más allá. Los iconos y las preguntas de prejuicios acercan a los unos con los otros. Una vez lo haya logrado, sigue su ruta hacia el segundo eslabón de la estrategia didáctica praccis.

\subsection{Segundo eslabón}

El segundo eslabón es el acercamiento a los saberes o el mundo de las ciencias, donde sus partes son la iconografía, las preguntas de reflexión, las preguntas de comprensión, el diálogo y los juegos para recrear el saber. El mundo de las ciencias, en este caso, está configurado por "Las redes tróficas y la productividad en la ciénaga de Ayapel", un discurso científico, que se construye con los conceptos, signos artificiales, que son palabras del mundo de la vida pero que representan un saber especializado en el mundo objetivo. Sobre ellas, el profesor, crea otro icono, un mapa conceptual que muestra ese saber científico en síntesis y lo acompaña de un glosario de conceptos (figura 4). Sobre él elabora preguntas para reflexionar y para comprender.

Se inicia un diálogo con un juego de palabras. Los otros, los habitantes de la ciénaga, conocen su entorno a través de palabras del lenguaje cotidiano; los profesores, investigadores de los procesos físicos, químicos y biológicos de la ciénaga, producen otro lenguaje. Los unos con los otros entran en comunicación. El profesor elabora preguntas para reflexionar y comprender.

Reflexionamos para evitar los malos entendidos, para salirnos de lo propio y acercarnos a lo ajeno, para subirnos en forma transparente en el círculo de la comprensión, para dialogar con lo otro, con lo que nos sorprende, con lo que nos llega, "bajo el concepto de reflexión caen todos los modos del aprehender" [10], en fin... reflexionamos 
para meditar. Las preguntas de reflexión son preguntas que siembran incertidumbre; son preguntas que incomodan y desacomodan; son preguntas que generan acontecimientos; son preguntas que tutelan el saber; son preguntas del tipo:

- Cuándo se alimenta con un pez de la ciénaga, ¿piensa cómo se ha alimentado ese pez?

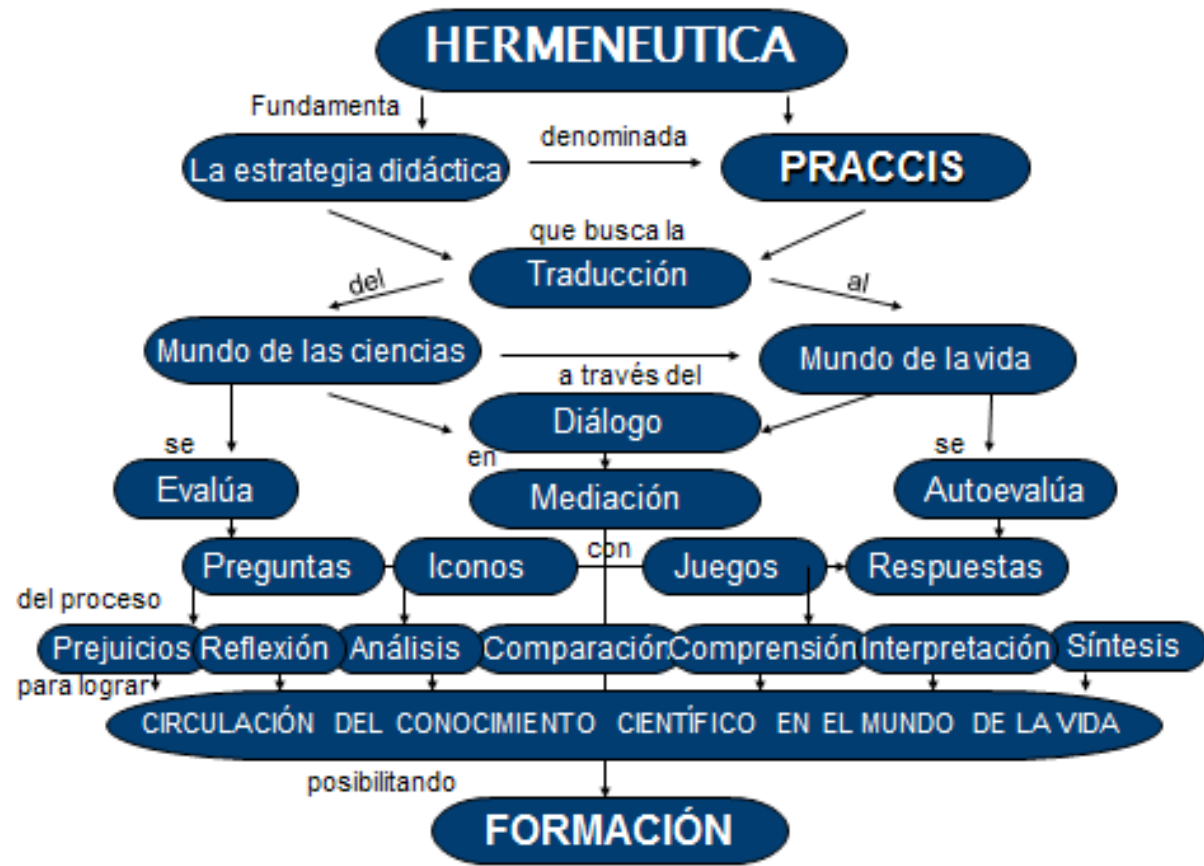

Figura 4. Mapa conceptual de la estrategia didáctica praccis Fuente: [4]

- ¿Ha estimado qué sucede cuando el sol calienta la ciénaga?

- ¿Ha apreciado cómo viven la materia y la energía en la ciénaga?

- ¿Ha considerado ser en parte responsable de las inundaciones que produce la ciénaga?

La vida misma se manifiesta en la ciénaga; eso otro se presenta ante nosotros como cosas diversas en las cuales centramos nuestra atención; pensar, apreciar, considerar, estimar son acciones que llegan a la conciencia y la mueven; eso otro que nos aborda: la alimentación, el sol, la materia, la energía, las inundaciones, otras cosas sobre la ciénaga, que nos hacen detener en el tiempo, salir de nosotros y meditar. Reflexionar. 
Sentimos y reflexionamos para estar a la expectativa del comprender. En la expectativa del comprender, en la pre-comprensión, se pregunta cómo una proyección de sentidos rueda al círculo de la comprensión, donde este primer proyecto de sentido será sustituido por otros más adecuados, en un proceso siempre abierto de círculos concéntricos que crecen con cada nueva pregunta y se comprende de otra manera, pero nunca en plenitud.

Comprendemos cuando hacemos propio lo ajeno, cuando actualizamos el saber, cuando aprendemos un sentido, cuando podemos algo, cuando nos podemos comunicar en ese otro lenguaje. Las preguntas de comprensión son preguntas que abren una conversación con el saber, son preguntas que denotan, son preguntas que mantienen abierta la marcha del discurrir. Son preguntas del tipo:

- ¿Cuáles son los componentes de un sistema cenagoso?

- ¿Qué es una red trófica?

- ¿Por qué hay ecosistemas más productivos que otros?

- ¿Dónde habitan las algas?

- ¿Cómo puede ser la cadena trófica?

El lenguaje especializado hace su ingreso. Entre los habitantes y la ciénaga surge otro lenguaje, construido por científicos que experimentan en aquel espejo de agua, y sus resultados necesitan ser conocidos por la comunidad para mejorar su nivel de vida (figuras 5 y 6). Por ello el profesor se comunica con preguntas del estilo ¿qué?, ¿cómo?, ¿dónde?, ¿por qué?, ¿cuáles? Oye a los interlocutores y se expone en el saber que él mismo ha construido, mientras se va exponiendo se acompaña de iconos y juegos para provocar la conversación con otros e ir percibiendo la comprensión.

Los iconos y los juegos son mediaciones. Los iconos son signos que funcionan en virtud de la semejanza existente entre la representación sígnica y lo representado, es "el único modo de comunicar directamente una idea" [12]. En su sencillez los iconos generan recordación, provocan la proximidad, las interacciones, el diálogo. Los juegos son una experiencia lúdica reglamentada. "El ser de todo juego es siempre resolución, puro cumplimiento, enérgeia que tiene en sí misma su télos" [8]. "El goce que produce (el juego) es el goce del conocimiento" [8].

Entre las preguntas para la comprensión, los iconos y los juegos, el profesor desea asegurar la comprensión; por ello entra en la didáctica praccis el tercer eslabón. 


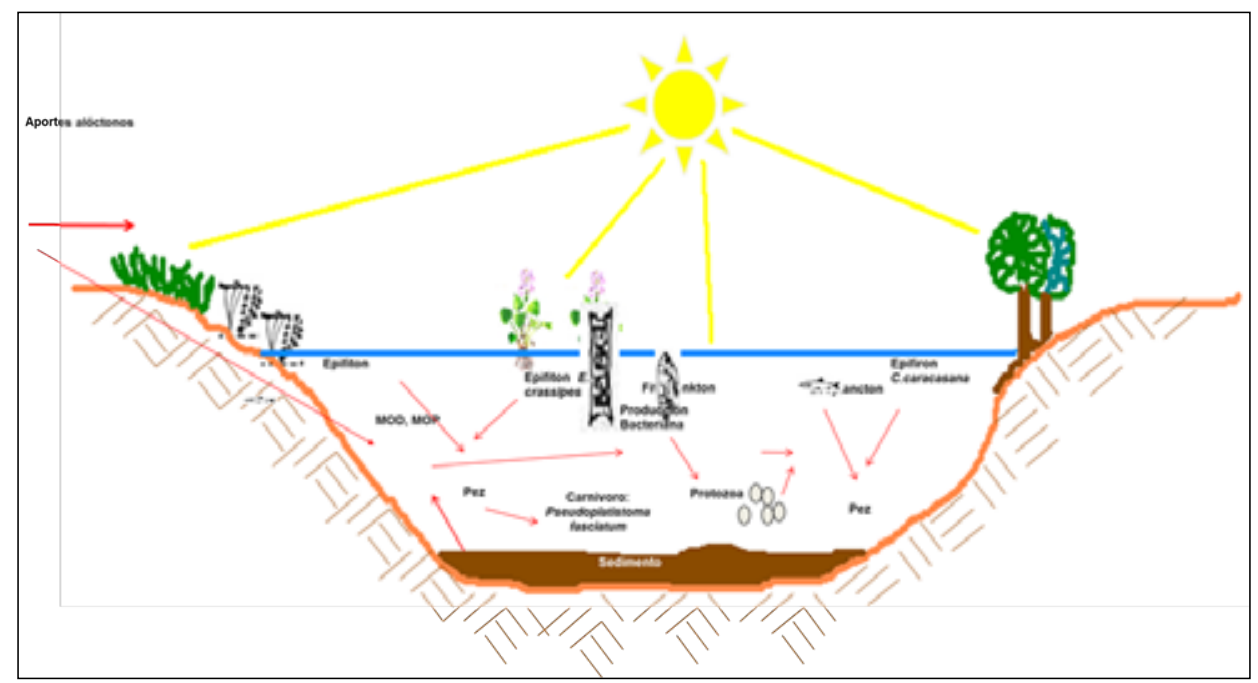

Figura 5. Red de pastoreo y una red detrito Fuente: [4]

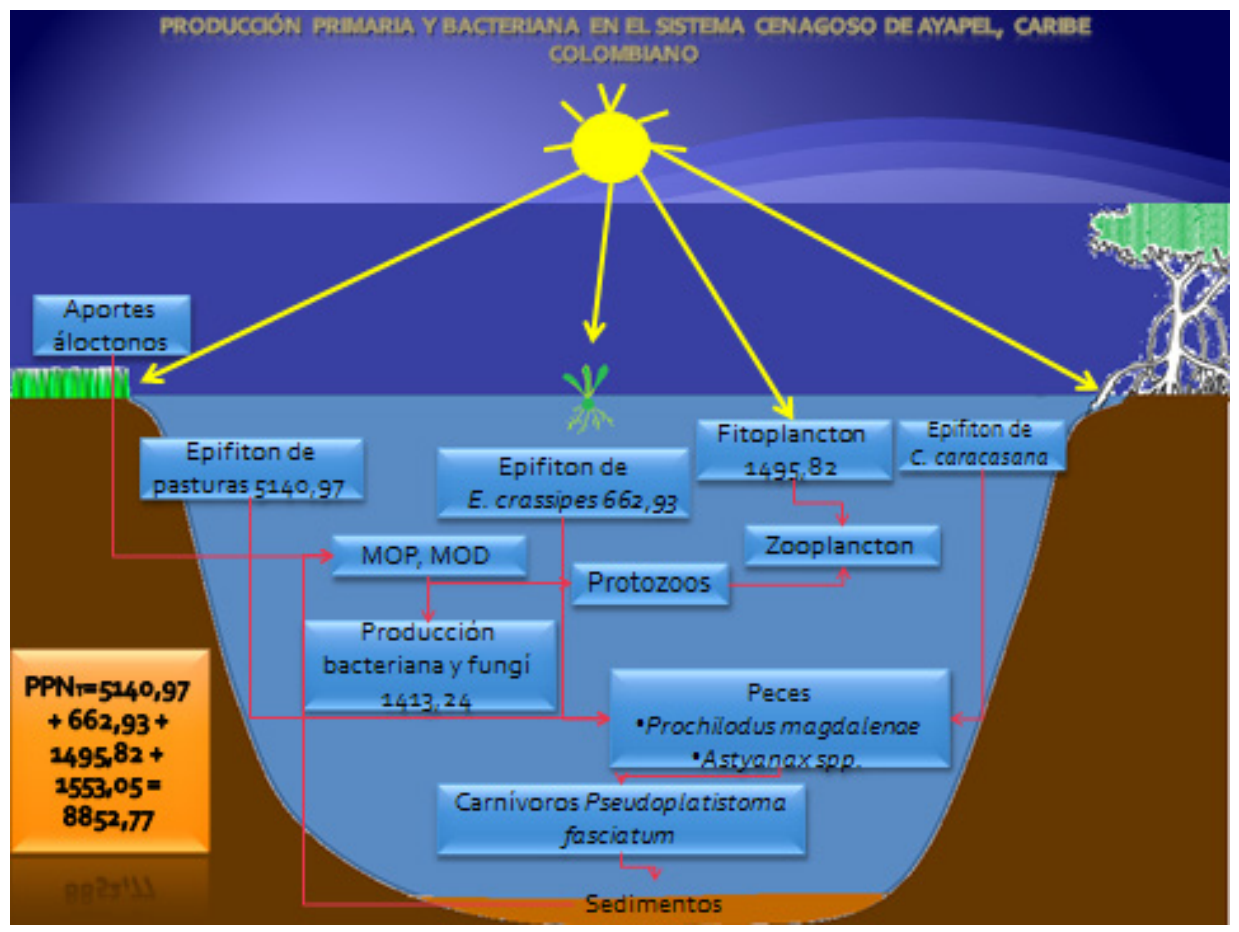

Figura 6. Valores de producción primaria neta (PPN) en $\mathrm{t} / \mathrm{km}^{2} / \mathrm{año}$ Fuente: [4] 


\subsection{Tercer eslabón}

El tercer eslabón involucra el aprendizaje de los saberes científicos como un todo, con sus respectivas partes; nuevamente la iconografía, los juegos y las preguntas, esta vez de análisis, de comparación, de interpretación y de síntesis. El círculo hermenéutico sigue girando y expandiéndose en su diálogo rumbo a la unidad de sentido, cuando ya no existirá algo extraño para el otro que penetra en el diálogo. El profesor propone entonces otra serie de preguntas para analizar y comparar, en verificación del movimiento de la pre-comprensión a la comprensión.

Se analiza cuando se descodifica, cuando se penetra en lo otro, cuando se desvelan las estructuras. Para ello el todo se divide en sus partes. Al descodificar también se ejerce la comparación, las partes se van cotejando, se trae eso otro que se sabe para ir comprendiendo una cosa a partir de otra, hallando los significados.

Las preguntas de análisis buscan ingresar en la cosa en cuestión, descomponer ese todo en sus partes. Las preguntas de comparación buscan establecer relaciones entre esas partes.

Las preguntas de análisis son del tipo:

- ¿Cómo se visualiza la productividad biológica en la ciénaga de Ayapel?

La cosa para ser analizada es la ciénaga de Ayapel desde una perspectiva de su productividad biológica, como un todo; entonces, ya los otros, estudiantes y pescadores, deben comprender el concepto de ciénaga, sistema cenagoso, ecosistema, productividad, redes tróficas, fotosíntesis, respiración, energía y materia, entre otros, como cada una de sus partes; cada uno de estos conceptos son necesarios para ir agregando significados a la cosa de la que se está hablando, en sentido general, la productividad biológica; en sentido particular, la productividad biológica en las ciénagas, y en términos singulares, en la productividad biológica de la ciénaga de Ayapel, donde se contextualiza el saber, que en realidad es del interés de sus habitantes.

Pero para analizar mejor la productividad biológica de la ciénaga de Ayapel, las preguntas de análisis se acompañan de preguntas para comparar, a saber:

- ¿Cómo se relacionan la productividad y el consumo en un sistema cenagoso?

- ¿Cómo interactúan la cadena de pastoreo y la cadena de detrito en una red trófica?

- ¿Cómo se diferencian la fotosíntesis y la respiración?

Relacionar, interactuar, diferenciar...

Al comparar lo que habita en la ciénaga se puede ir ahondando en el análisis, bifurcándose en caminos que traen otros saberes y van complementando el análisis. Ellos, 
el análisis y la comparación, mejoran la comprensión. La comprensión "nos confiere la posibilidad de apropiarnos de lo ajeno" [13] y hacer cosas con ello, "el mundo ya comprendido resulta interpretado" [14].

La interpretación nos lleva a la práctica pues "la forma de realización de la comprensión es la interpretación” [8]. La interpretación es eminentemente aplicativa. Es aquello que vamos haciendo con lo que comprendemos y para ello vamos anudando otros saberes que afloran. Las preguntas de interpretación son preguntas útiles, son preguntas pragmáticas, son preguntas que fusionan horizontes. Son preguntas del tipo:

- ¿Cómo afecta la contaminación acuática la productividad en la ciénaga de Ayapel?

- ¿Cómo se relaciona la producción biológica de la ciénaga de Ayapel con la economía familiar?

Preguntas que llevan el saber de las ciencias a la vida diaria: la contaminación afecta la ciénaga, la producción biológica afecta la economía familiar; se entrecruzan horizontes que perturban el orden y provocan en quien aprende otras cosas que trae de su ser en el mundo, añade cosas a lo expuesto por el profesor y empieza no solo a estar ahí, sorprendido y conmovido por un saber sino a concienciarse y aportar. Ahí, cuando encuentra algo que crear, es el momento de la síntesis, el profesor se va desvaneciendo pues se ha quedado en el otro. Es el paso de la significación al sentido.

La síntesis es la producción de algo nuevo, algo propio, desde un punto de visto singular, sobre lo comprendido e interpretado, pues "de hecho todo encuentro con una obra posee el rango y el derecho de una nueva producción" [8]. Hacer síntesis es encadenar un texto nuevo, según un punto de vista, al texto en interpretación. Las preguntas que motivan las síntesis son preguntas ocurrentes, del tipo:

- ¿Cómo se puede aprovechar la energía solar para la producción de peces en un estanque?

Esta pregunta necesita no solo comprender e interpretar el concepto de productividad biológica sino poner en acción eso que sabe con eso que imagina, para crear algo en el mundo de la vida.

Este diseño de la estrategia didáctica praccis, que inicia con la motivación y los prejuicios, que es atravesado por las preguntas, los iconos y los juegos, y que culmina momentáneamente con la creación de algo está penetrado por la conciencia del profesor y del estudiante al ejercer la evaluación y la autoevaluación, como un acompañante permanente. Es el cuarto y último eslabón. 


\subsection{Cuarto eslabón}

El cuarto eslabón consiste en la evaluación y la autoevaluación o la formación del ser. La estrategia didáctica praccis se construye sobre el concepto de hermenéutica, en tanto "el cultivo del diálogo" [13]. Ese diálogo busca hacer propio lo ajeno, evitar el mal entendido, discurrir con el conocimiento, llegar a acuerdos, tomar conciencia, formarse. El diálogo, lo que se dice, lo que se escucha, lo que promueve son la fuente de la evaluación y la autoevaluación. Cada pregunta, cada respuesta, cada icono, cada juego posibilitan que ese saber se deposite en el otro; eso es la que valora el profesor, es la evaluación. El saber más de sí mismo, el construirse su imagen conscientemente con lo aprendido y el crear formas de ser en el mundo de la vida es la autoevaluación. Cuando el profesor puede hablar sin traducir, de esa parte de su saber, con los otros, y para ellos ya no hay nada extraño ni lejano en lo dicho, se llega a la unidad de sentido, al menos por un momento.

Son preguntas de evaluación que generan la autoevaluación:

- ¿Qué sentido tiene para los habitantes de la ciénaga de Ayapel conocer los procesos de producción biológica en ese espejo de agua?

Para responder esta pregunta, el que aprende debe comprender qué produce la ciénaga, cómo lo produce, cómo mejorar esa producción, qué necesidades tienen los habitantes de la región y cómo la productividad de la ciénaga puede satisfacer algunas de estas necesidades. Es decir, comprende un conocimiento científico y lo pone a disposición de los demás y al suyo propio, se sabe en su historia y toma conciencia de ello, se está formando (figura 7).

\subsection{La vivencia de praccis}

El taller praccis se realizó en la orilla del sistema cenagoso de Ayapel, cerca al casco urbano en el sitio "Mi Ranchito". El sistema cenagoso de Ayapel es un conjunto de ciénagas ubicado en el suroeste del departamento de Córdoba en la república de Colombia. La zona hace parte del bioma denominado depresión Momposina. La superficie de agua del sistema cenagoso de Ayapel ocupa un área máxima de $140 \mathrm{~km}^{2}$ en el mes de noviembre en aguas altas, y se reduce a $40 \mathrm{~km}^{2}$ en el mes de marzo en aguas bajas. El espejo de agua se encuentra a $22 \mathrm{msnm}$, su agua es cálida (temperatura del agua > $25^{\circ} \mathrm{C}$ ) y es un sistema que posee alta diversidad biológica [1].

El taller sobre redes tróficas y productividad se realizó el 16 de febrero de 2012 y a este asistieron 48 personas entre pescadores, pobladores, estudiantes, profesores y autoridades municipales, quienes fueron convocadas por Corpoayapel. El taller de circulación del conocimiento empleando la estratégica praccis [15] inició a las 8:00 a. m. y finalizó a la 1:00 p. m. 




Figura 7. Mapa conceptual de praccis Fuente: [4].

Para el desarrollo del taller se tuvieron en cuenta los siguientes pasos:

1. Introducción con una duración de 10 minutos.

2. Taller de prejuicios de la comunidad, con una duración de 20 minutos.

3. Conferencia sobre redes tróficas y productividad en el sistema cenagoso de Ayapel con una duración de 25 minutos.

4. Entrega de texto: Redes tróficas y productividad en el sistema cenagoso de Ayapel, Colombia.

5. Realización de juegos para la asimilación del conocimiento científico, con una duración de 25 minutos.

6. Comprensión de la socialización, con base en preguntas elaboradas previamente, con una duración de 20 minutos.

7. Propuestas por parte de la comunidad sobre el cuidado de la ciénaga de Ayapel, con una duración de 20 minutos.

8. Evaluación a partir de un instructivo que portaba las siguientes preguntas:

1. ¿Le gustó la cartilla? SÍ $\mathrm{NO}$ ¿Por qué?

2.¿Cuáles actividades realizó durante el desarrollo del taller 
3. ¿Cuál actividad le gustó más? ¿Por qué?

4. ¿Cómo se sintió en el desarrollo del taller? ¿Por qué?

5. ¿Qué haría en el diario vivir con lo que aprendió hoy?

6. ¿Qué beneficios tienen para usted los estudios sobre esta ciénaga?

Para el análisis de la información se eligieron al azar 11 personas que desarrollaron el aplicativo de evaluación. La información obtenida fue procesada en Excel clasificando las respuestas según campos semánticos. Se efectuaron los conteos para cada campo semántico dentro de cada pregunta. Se construyeron figuras de barras para observar las frecuencias de aparición de los campos semánticos en cada pregunta. Posteriormente se compararon las frecuencias entre preguntas teniendo en cuenta las respuestas sí y no en cada pregunta.

Se analizó la información organizando la base de datos y clasificando las frecuencias según dos fuentes de variación: pregunta y campo semántico. Se realizó un análisis de componentes de varianza. Cuando al menos un factor o fuente de variación influyó en más de un $30 \%$ de la variación de los datos se empleó una ANOVA de I, vía no paramétrica correspondiente a la prueba de Kruskal-Wallis. Para el análisis de los datos se empleó el programa Statgraphics-millenium.

Los resultados se presentan en la figura 8, en donde se muestran los conteos para cada pregunta y cada campo semántico de 11 evaluaciones aplicadas a personas que asistieron al taller sobre redes tróficas y productividad en el sistema cenagoso de Ayapel.

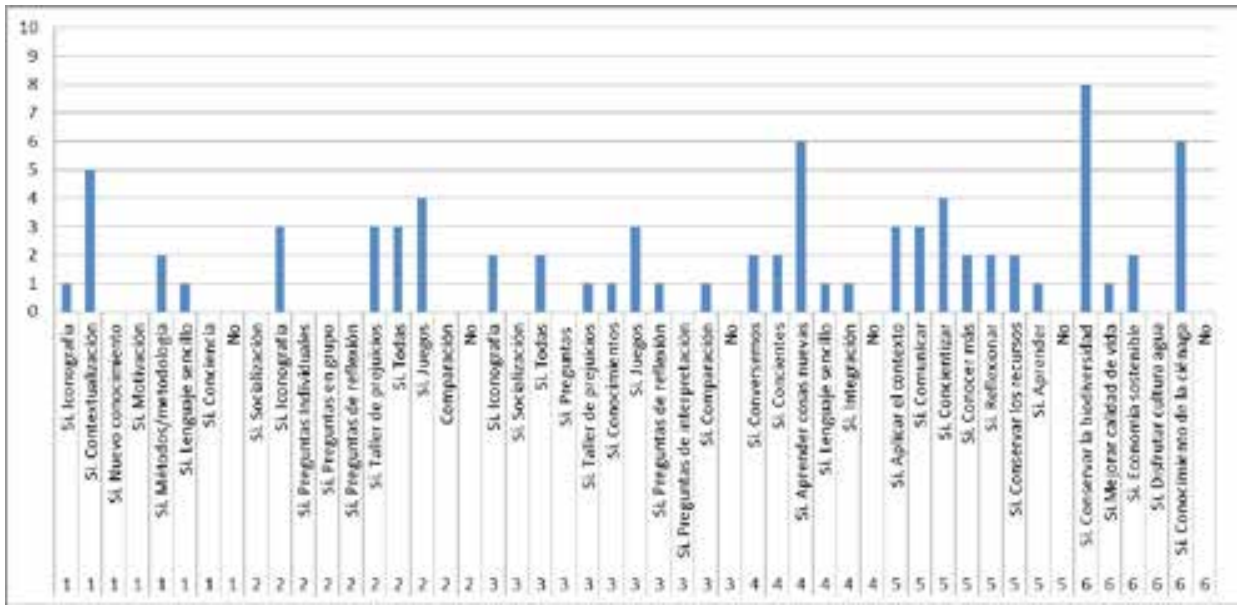

Figura 8. Mosaico de campos semánticos por pregunta.

Fuente: elaboración propia 
Los campos semánticos que se fueron constituyendo están ligados a los eslabones de la estrategia didáctica y a los procesos de aprendizaje que generaron: en la primera opción se percibe el taller de prejuicios (contextualización, aplicar el contexto, socialización, preguntas en grupo, conversemos, comunicar, integración) como el momento de la estrategia que más gustó, seguido de los juegos, la iconografía y las preguntas, en sus diferentes clasificaciones; entre los aprendizajes que se generaron se percibe que la concienciación y el adquirir nuevos conocimientos, cuando son contextualizados es lo más representativo. La alusión al uso del lenguaje sencillo es bastante representativa para la comunidad a la que iba dirigido ese saber producto de investigaciones científicas.

El análisis de varianza ACV tuvo en cuenta, como factores, pregunta y campos semánticos.

El factor que más contribuye a la varianza fue campos semánticos. Su contribución representó el 98,65\% de la variación total en los conteos. Se aplicó una prueba de Kruskal-Wallis para los campos semánticos (estadístico $=45,7779$ valor-P $=0,105007$ ). Dado que el valor-P es mayor o igual que 0,05 , no existe una diferencia estadísticamente significativa entre las medianas con un nivel del 95,0 \% de confianza. Es decir, que las diferencias entre campos semánticos no fueron estadísticamente significativas.

\section{CONCLUSIONES}

La estrategia didáctica praccis fue vivida como una experiencia única e irrepetible para cada poblador de la región que participó en el taller. Fue aceptada en su totalidad como motivadora y clara, como una mediación que posibilita la circulación del conocimiento producido por los científicos hacia los habitantes de la región, quienes, contextualizados en su medio, pueden tomar consciencia de su entorno y posibilitar acciones hacia la conservación de su biodiversidad.

Los habitantes viven la ciénaga con su lenguaje cotidiano, pero con esos datos extraños, obtenidos por los científicos y traducidos a su lenguaje común generan una conversación que alimenta tanto a investigadores como a pobladores para el beneficio común: el desarrollo sostenible de la ciénaga de Ayapel.

La filosofía, en este caso la filosofía hermenéutica, sirve de presupuesto para que la didáctica pueda leer un saber y traducirlo para todos; es la filosofía cercana, vivida, para crear forma de ser en el mundo que habitamos. La conversación y la lúdica envuelven los saberes extraños para acercarlos, sin perder su estatus de cuasi ciertos, y disfrutarlos para mejorar el nivel de vida de los pobladores de la región.

Los campos semánticos y su relación con los eslabones de la estrategia praccis fueron atractivos para los pobladores de Ayapel, es decir, que ellos están interesados 
en la circulación del conocimiento del sistema cenagoso de Ayapel dado que encuentran en él una posibilidad de relacionarse con los ecosistemas desde una perspectiva sostenible y responsable.

\section{AGRADECIMIENTOS}

Los autores agradecen al comité de desarrollo de la investigación de la Universidad de Antioquia CODI, a las facultades de Educación e Ingeniería, a la Corporación Académica Ambiental, y a CorpoAyapel.

\section{REFERENCIAS}

[1] N. Aguirre y E. González. "Redes tróficas y productividad en el sistema cenagoso de Ayapel, Colombia," Texto de divulgación científica. Sello Editorial Universidad de Medellín. ISBN. 978-958-8692-44-9. Medellín, Colombia. P. 49, 2011.

[2] Ramírez, Viña G. "Limnología colombiana: aportes a su conocimiento y estadísticas de análisis”. Primera edición. Editorial Panamericana. Bogotá, Colombia. 1998.

[3] Ramsar. "La Convención de Ramsar". Oficina de la Convención Ramsar, UICN, Gland, Suiza. 22 p. 1992.

[4] N. Aguirre, O. Caicedo y E. González, 2011. Las plantas acuáticas del sistema cenagoso de Ayapel Córdoba, Colombia. Texto de divulgación científica. Sello Editorial Universidad de Medellín. ISBN. 978-958-8692-49-4. Medellín, Colombia. 49 páginas.

[5] Y. Montoya, N. Aguirre, y E. González. "El Perifiton del sistema cenagoso de Ayapel, Córdoba, Colombia”. Texto de divulgación científica. Sello Editorial Universidad de Medellín. ISBN. 978-958-8692-42-5. Medellín, Colombia. 81 páginas. 2011.

[6] Gadamer, Hans-Georg. Verdad y método II. Salamanca: Sígueme. 2002

[7] Dilthey, Wilhelm. "Dos escritos sobre hermenéutica: el surgimiento de la hermenéutica y los esbozos para una crítica de la razón histórica”. Madrid: Itmos. 2000.

[8] Gadamer, Hans-Georg. Verdad y método I. Salamanca: Sígueme. 1997.

[9] Habermas, J. “Teoría de la acción comunicativa I: 3. Relaciones con el mundo y aspectos de la racionalidad de la acción de cuatro conceptos sociológicos de acción”: 110-146. España: Taurus. 1999.

[10] Husserl, E. “Ideas relativas a una fenomenología pura y una filosofía fenomenológica”. México: Fondo de Cultura Económica. 1995.

[11] Hoyos Vásquez, G. "La ética fenomenológica. En A propósito de Edmund Husserl y su obra". (pp. 59-130). Parte de: Husserl, E. Filosofía primera (1923/24). España: Grupo Editorial Norma. 1998 
[12] Pierce, Charles Sanders. El hombre, un signo (Título original: TheCollectedpapers of Charles Sanders Peirce). Editorial Crítica. Barcelona. 428 p. 1988.

[13] Gutiérrez, Carlos B. Temas de filosofía Hermenéutica. Bogotá: Uniandes. 2002.

[14] Heidegger, M. “El ser y el tiempo”. Santafé de Bogotá: Fondo de la Cultura Económica. 1993.

[15] González, E., Aguirre, N., Grisales, L., Giraldo, G., Villabona, S., Uribe, E., \& Velásquez, D. PRACCIS: "una estrategia didáctica basada en la hermenéutica para la circulación de los conocimientos o acerca del desarrollo de una prueba piloto". Revista Gestión y Ambiente. Mayo 2012: 15 (1): 151-164. ISSN 0124.177X. 2012. 